\title{
Progressões Aritmética e Geométrica: uma análise Histórica do caderno de uma ex-aluna do curso de Ciências
}

\author{
Ikaro de Oliveira Trabuco \\ Joubert Lima Ferreira
}

\section{Resumo}

$\mathrm{O}$ artigo teve objetivo analisar historicamente o conteúdo progressões aritmética e geométrica presentes no caderno da disciplina Matemática do Curso de Ciências da Faculdade Estadual de Educação de Feira de Santana (FEEFS). O Caderno em análise foi utilizado por Celina Bacellar, quando do seu processo de formação profissional, especificamente em 1974. A partir da análise do conteúdo e do cruzamento de outras fontes e materiais históricos foi possível estabelecer relações entre o contexto socioeconômico da década de 1970 e o desenvolvimento de Feira de Santana, período que ocorreu a interiorização do ensino superior com a abertura da FEEFS. Assim, foi possível perceber o modo como foram registrados os conteúdos das aulas, metodologias e instrumentos utilizados, além de estabelecer uma comparação do conteúdo com livros de Scipione e Jacy Monteiro, muito usados e que circularam no período citado.

Palavras-chave: Matemática; Caderno escolar; Análise; História; Educação. 


\section{Arithmetic and Geometric Progressions: a Historical analysis of the school notebook of a former student of science course}

karo de Oliveira Trabuco

Joubert Lima Ferreira

Abstract

The aim of the article was to analyze the arithmetic and geometric progression presents in the notebook of the Mathematical discipline of the course of Sciences of the Faculdade Estadual de Educação de Feira de Santana (FEEFS). The Notebook in analysis was used by Celina Bacellar during her professional training process, specifically in 1974. From the analysis of the content and crossing of other historical sources and materials it was possible to establish relationships between the socioeconomic context of the 1970 and development of Feira de Santana, period that occurred the interiozation of higher education with the opening of the FEEFS. Thus, has been possible to perceive how the lessons contents, methodologies and instruments used were recorded, as well as to establish a comparison of the content with books of Scipione and Jacy Monteiro, widely used and circulated during the mentioned period.

Keywords: Mathematics; School notebook; Analysis; History; Educaction. 


\section{Introdução}

Por muitas vezes esquecidos na prateleira ou em algum canto, os cadernos escolares têm grande importância no estudo historiográfico do ensino de matemática, revelando formas de fazer, ensinar e desenvolver conhecimentos matemáticos. Este instrumento traz a possibilidade de registrar e guardar ao longo do tempo marcas de um passado, tornando possível a sua representação. O caderno também é uma importante fonte primária para pesquisas, pois, dotados de pessoalidades e escritos à mão, mostra a percepção do aluno, permitindo o acesso aos indícios do que ocorria em sala de aula (RHEINHEIMER; DALCIN, 2017).

O caderno do qual se trata a presente pesquisa foi utilizado por Celina Bacellar, uma estudante do curso de licenciatura em Ciências da Faculdade Estadual de Educação de Feira de Santana (FEEFS). Salienta-se aqui o método de ensino empregado na época (1970), a Pedagogia Tecnicista na qual era priorizado a mera transmissão de conhecimentos, sem levar em consideração o contexto e apenas instrumentalizar para o mercado de trabalho. Um outro fator de destaque é o Movimento da Matemática Moderna que trouxe uma relação entre a matemática enquanto ciência e o ensino básico, sofrendo influência da concepção Boubarkista. Nesse cenário a formação de professores das licenciaturas curtas tinha como objetivo formar profissionais generalistas, que conseguissem lecionar diversas matérias, minimizando a falta de professor diante da demanda de vagas criadas em escolas públicas após a Lei no ${ }^{0}$.692/71.

A Faculdade foi instalada em Feira de Santana, por ser uma cidade que tinha um grande potencial de desenvolvimento e em prol da interiorização do ensino superior. Foi criado um plano emergencial, na tentativa de suprir a demanda de professores do ensino básico, isso fez com que licenciaturas curtas fossem criadas, não sendo esta a melhor solução, visto que seria uma formação com período menor, impactando na qualidade da mesma. No ano de 1974 a estudante se fazia presente nesse meio acadêmico, trazendo em seu caderno a possibilidade de ter acesso a elementos que possibilitam uma aproximação das aulas, das atividades propostas, como eram registrados, entre outros aspectos.

Este trabalho tem por objetivo analisar historicamente o conteúdo progressões aritmética e geométrica presentes no caderno da disciplina Matemática do Curso de Ciências da Faculdade Estadual de Educação de Feira de Santana. O acesso ao caderno foi possível a partir de documentos digitalizados pelo segundo autor para a sua pesquisa de doutoramento, por se tratar de um documento histórico, foi trabalhado a partir da digitalização, em função do desgaste causado pelo tempo. A análise foi realizada através da leitura e observação atenta dos registros e posteriormente comparada com dois livros Matemática Na Escola Renovada de Scipione (1973) e Matemática Curso Moderno de Monteiro (1972) escritos naquela época. 
Portanto, esse estudo apresenta relevância no campo da História da Matemática e do seu ensino, pois promove o conhecimento do que foi vivenciado na primeira faculdade de formação de professores de Feira de Santana, possibilitando a percepção da metodologia utilizada e como eram abordados os conteúdos matemáticos. Inicialmente, procuramos discutir a importância das pesquisas em cadernos, a fim de mostrar a relevância destes na vida do estudante, sendo um produto da cultura escolar, evidenciando as práticas de ensino, atividades, e o modo que o aluno seguia suas anotações. Neste sentindo, fez-se necessário apresentar como se dava os saberes no processo de profissionalização, abordando também o processo de interiorização do ensino superior e a abertura da faculdade e por fim a análise do caderno de Celina Bacellar.

\section{$O$ caderno e as pesquisas sobre cadernos}

O caderno escolar tem grande importância na vida do estudante, servindo como instrumento para registrar aprendizados e possibilitando a revisão posterior. Nessa mesma função, serve como material histórico, pois, pode guardar ao longo dos anos a história do ensino de diversos conteúdos e seu desenvolvimento na linha do tempo. (MIGNOT, 2008)

De acordo com Rheinheimer e Dalcin (2017) o caderno é um produto da cultura escolar, assim como documentos, formas de ensino, diários, trabalhos e provas. A utilização dos mesmos se mostra como uma possibilidade de inserção nesta cultura, a partir desses documentos pode-se problematizar, investigar, questionar e descrever as práticas pedagógicas que se passavam em um momento histórico, revelando assim ideologias e relações de poder. (COSTA; AMARAL, 2017). Nesse sentido, como aponta Rheinheimer e Dalcin (2017, p. 3):

Os cadernos podem trazer informações importantes sobre quais e como eram abordados os temas de estudo, por meio de sua análise buscamos indícios do que ocorria em termos de ensino e organização da e na sala de aula, as práticas e rotinas vigentes.

A produção de estudos científicos sobre os cadernos escolares promove por meio da problematização a investigação e análise de aspectos como o contexto histórico em que está inserido, práticas de ensino, costumes diários, a relação que se estabelecia entre professoraluno, tipos de atividades realizadas, além de pontuar a forma como eram organizados e expostos os conteúdos (COSTA, 2017). Desse modo formam fontes essenciais quando se busca compreender, por registros escritos, o que já foi produzido na escola por seus atores sociais, articulados em um tempo único (RIOS; FISCHER, 2017).

É importante ressaltar a singularidade de cada caderno, destacando que os mesmos possuem uma história pessoal, que ao ser interrogada trazendo possibilita 
compreender os modos de fazer educação do passado, permitindo assim que possamos representar uma realidade já vivida, mesmo que essa não possa ser reproduzida, porém tentase aqui ter uma ideia de como foi vivenciá-la. Luz e Rios (2017) afirmam que

Os pesquisadores na área da História da Educação, contam com diversas fontes de pesquisa sendo que essas se complementam e nos conduzem para um entrosamento sobre o assunto investigado, logo percebemos que cada uma das fontes nos apresenta vestígios de diferentes atividades humanas, e, os cadernos, no caso, atividades relacionadas às práticas didáticas realizadas pelos alunos nas salas de aula.

O caderno escolar se mostra como uma importante fonte para as pesquisas em História da Educação Matemática, pois foram utilizados pessoalmente, escritos à mão, dotados de particularidades, mostrando a percepção do aluno frente ao ensino da época e elementos da prática do professor, por meio destes procura-se indícios do que ocorria em sala de aula (RHEINHEIMER; DALCIN, 2017). O estudo da história com instrumentos usados na época traz consigo dados do cotidiano registrados, desenhos, cálculos, descrições e anotações cheias de conteúdos e é isso que permite o conhecimento do passado (LUZ; RIOS, 2017).

Um ponto interessante nesse objeto de estudo é que a pesquisa se baseia no que foi registrado pelo aluno, permitindo uma compreensão maior da percepção do aluno frente aos métodos de ensino, atividades e conteúdo. Como foi lembrado por Rios e Fischer (2017) que a utilização desses meios pode oferecer para a produção historiográfica, percepções distintas dos professores a respeito das práticas educativas, mas é preciso diferenciar: não se pode considerar todo o registro como se fosse realizada livremente pelo aluno. Já que sempre houve mediações e controle do docente, por isso é necessário estar atento ao que é conteúdo espontâneo e o que foi cobrado.

Rheinheimer e Dalcin (2017) apontam o caderno como um regulador do tempo e da matéria escolar, sendo que por meio da prática de atividades que o professor percebe a produção do aluno e do grupo, de acordo com os autores, o registro de datas acaba marcando o que foi realizado.

O material utilizado aqui para análise se trata de um caderno usado durante a formação de um professor de Ciências, no ano de 1974. Dentro desse contexto, objetiva-se analisar historicamente o conteúdo progressões aritmética e geométrica presentes no caderno da disciplina Matemática do Curso de Ciências da Faculdade Estadual de Educação de Feira de Santana. Esta tem grande importância social, principalmente pelo contexto histórico da época em que a instituição onde utilizaram o caderno foi uma das pioneiras em Feira de Santana a oferecer ensino superior na área (FERREIRA, 2017). Visualizar esses detalhes pode permitir a identificação futura de variáveis que influenciam de forma positiva ou negativa no ensino na 
realidade brasileira e assim criar melhores formas de fazê-lo. Nesse sentindo, propõe-se olhar para os registros do material de pesquisa e identificar diferenças e semelhanças ao longo do tempo, pois como ressalta Ferreira (2017, p. 19):

Todo o percurso que envolve formar/ser/estar professor de matemática, produzir material e livros didáticos, experimentar, treinar são elementos constitutivos da profissionalização docente que, levando em consideração a história cultural, pode ser entendido como dinâmico, complexo e multidimensional.

Para isso, faz-se necessário trazer para discussão os saberes que o professor de matemática aprende durante esse processo de profissionalização, quais os conteúdos que o formam, o que vem a ser sua referência no exercício de docência (VALENTE, 2017).

\section{Os saberes no processo de profissionalização}

Para tratar sobre os saberes envolvidos nesse processo, se faz necessário explicitar os métodos de ensino que eram utilizados naquele período. Em 1970, a linha de ensino empregada na época era a pedagogia tecnicista, que tinha o foco na tecnologia educacional, priorizando a transmissão de conhecimentos, tendo alunos e professores como receptores e executores de atividades, sem estabelecer uma relação com o contexto vivenciado (MENEZEZ; SANTOS, 2001).

No fim da década de 1950 e início da década de 1960, o ensino da matemática passava por reformulações curriculares e metodológicas que ficaram conhecidas como Movimento da Matemática Moderna (MMM). O MMM teve como principal objetivo trazer o que era produzido na matemática enquanto ciência para o ensino básico, juntamente com o desenvolvimento de novas metodologias para que assim as pessoas, de modo geral, pudessem acompanhar o crescimento tecnológico. A partir disso, foi necessário preparar os professores para ensinar e se apropriar dos conhecimentos que antes não eram vistos, como estrutura algébrica, teoria dos conjuntos, topologia e transformações geométricas (WIELEWSKI, 2008).

Em 1959 no Seminário de Royaumont, o MMM sofreu forte influência da concepção Boubarkista, onde a matemática é concebida como uma ciência na qual sua evolução mostra cada vez mais a sua unidade, tendo um método e objetivo próprio. Essa forma de pensar a matemática possuí três conceitos base consistindo em: a unidade da Matemática, o método axiomático e o conceito de estrutura matemática. O primeiro diz respeito a matemática como uma unidade, ideia que foi confrontada ao longo do tempo e que Boubarki propõe afirmando que mais do que nunca as teorias matemáticas tem sidos interelacionadas. $\mathrm{O}$ método axiomático consiste na busca profunda das razões para as descobertas matemáticas, que estão escondidas nos detalhes de cada teoria. Já estrutura são consideradas o único objeto da 
matemática, definida por propriedades que obedece a determinadas relações entre os elementos de um dado conjunto (GUIMARÃES, 2007).

Frente a essas formas de fazer e pensar matemática da época, o processo de profissionalização dos futuros professores perpassa por saberes essenciais, teorizado por Valente (2017) saberes para ensinar e saberes $a$ ensinar, o primeiro se trata dos conteúdos de formação profissional, técnicas pedagógicas, didáticas, entre outras que os formam para ensinar. Já o segundo diz respeitos aos conteúdos matemáticos propriamente ditos, que serão explicados em sala de aula. Condizendo com essa ideia, Francisco e Nacarato (2008, p. 3) trazem que:

Os professores nesse processo de profissionalização devem possuir um conjunto de conhecimentos e de técnicas necessárias ao exercício qualificado da atividade docente. Seus saberes não são teóricos apenas e nem tampouco instrumentais, deverá também tender para o contato cada vez maior com as disciplinas cientificas.

A relação dos professores com os saberes constitui o ponto central da profissão docente. Nóvoa (1995) nos lembra da importância da formação desses saberes e os espaços que as promovem, produzindo e reproduzindo conhecimentos e normas da profissão, sendo protagonistas na construção de conteúdos pedagógicos.

Essas escolas produzem a profissão docente, contribuindo para a disseminação entre os seus membros e para a história da profissão (NÓVOA, 1995). Os espaços formam conteúdos e junto com eles constituem os referenciais para o exercício da docência, dentro desse acervo teórico tem-se como saberes para ensinar segundo Valente (2017), ensinos de pedagogia teórica e prática, psicologia, ciências da educação, didáticas e metodologias das diferentes disciplinas escolares. E dentro dos saberes a ensinar que estabelece solidamente a formação, têm-se os conteúdos característicos do campo disciplinar de cada especificidade científica, como foi descrito por Valente (2017, p. 215):

A formação do professor de matemática tem nas rubricas de cunho matemático, da produção decantada ao longo do tempo por matemáticos, sistematizada e organizada em forma de disciplinas, a sua caracterização. Cálculo Diferencial e Integral, Álgebra Linear, Vetores e Geometria etc., são exemplos da "matemática a ensinar" que compõem a formação do licenciado em matemática. Da mesma forma, Matemática, Desenho, Geometria, entre outros, são referências do saber matemático presente, a depender da época histórica, na formação de docentes dos anos iniciais escolares.

Vale ressaltar que esses saberes mudam ao longo do tempo, podendo variar de uma categoria para outra, ou simplesmente ser retirada ou adicionada uma nova disciplina. Essas duas categorias deveriam estar interligadas, sendo os saberes a ensinar, conteúdo a ser 
ensinado pelo docente e os saberes para ensinar, conteúdos instrumentais, essenciais para que o professor possa traduzir os primeiros de uma forma que possa ser compreendido e assimilado pelos alunos.

\section{A Faculdade Estadual de Educação de Feira de Santana}

A segunda metade da década de 1950 foi marcada por lutas em Feira de Santana em prol da interiorização do ensino superior público na Bahia, que culminou na implantação da primeira Faculdade Estadual de Formação de Professores que foi chamada de Faculdade Estadual de Educação de Feira de Santana (FEEFS), esta posteriormente veio a ser a Fundação Universidade de Feira de Santana (SANTOS, 2011).

O processo de interiorização do ensino surge como uma proposta do governo estadual de Luiz Viana Filho (1935-1986), a partir da necessidade de ensino causada pelo surto industrial no interior baiano, na tentativa de suprir essa falta de ensino e de profissionais habilitados para educar, forma-se então o Plano de Emergência e o Plano Integral de Educação e Cultura (PIEC), que tinham como objetivo principal o aumento e reorganização da rede de ensino básico nas pequenas cidades. De acordo com Chapani (2012, p. 149) sobre estes planos:

Como parte do Plano de Emergência o governo fez aprovar a nova Lei Orgânica do estado, reestruturando o setor educacional, e promoveu uma reforma administrativa, modificando a estrutura da SEC. O PIEC, de orientação tecnocrática e identificado com os pressupostos do capital humano, realizou um diagnóstico da situação educacional no estado com correspondentes propostas de intervenção, especialmente em áreas até então pouco assistidas, provocando a ampliação da matrícula da educação básica e colocando o ensino público superior sob a iniciativa estadual, promovendo sua interiorização.

A reforma de emergência do ensino, feita pelo governo estadual, no período militar, resultou na abertura de instituições com cursos de curta duração, esses cursos visavam uma solução rápida e prática para profissionalização de jovens e formação de professores para adentrar ao ensino básico, assim surge a Faculdade Estadual de Feira de Santana em 1968. Cidade esta vista como estratégica tanto na industrialização como para o processo de formação de professores, promovendo acesso mais rápido e fácil para pessoas do interior.

Uma das metas do PIEC foi à criação de polos de educação, baseada na teoria dos polos de desenvolvimento. Deste modo, pesquisas apontam que a cidade de Feira de Santana era vista como um potencial de desenvolvimento, uma vez cortada pelas BR 101, 116 e 324, um dos maiores anéis viários do país, tornando-se um centro em forte expansão comercial, o que possibilitou ao Governo do Estado iniciar o processo de implantação de uma Faculdade de Educação (FERREIRA, 2017, p. 16). 
Santos (2011) afirma sobre o PIEC que o objetivo se desdobrava em criar unidades no interior com cursos de licenciatura para formar professores de $1^{\circ}$ ciclo do ensino médio. Essas escolas pretendiam formar em três anos, com currículos mínimos profissionais tidos como generalistas, para que com essa formação pudessem assumir diversas disciplinas. Professores de português e línguas estrangeiras (curso de letras), professores de história, geografia, organização social e política (estudos sociais) e professores de ciências naturais e matemática (curso de Ciências).

Instalada em 1968 a FEEFS tem seu início com o Curso de Letras, seguido do Curso de Estudos Sociais e o Curso de Ciências e Matemática em 1970, coordenado pela professora Maria Cristina de Oliveira Menezes (BOAVENTURA, 2005). A instituição funcionava na sede da antiga Escola Normal de Feira de Santana, localizada na Rua Conselheiro Franco, $\mathrm{n}^{\circ}$ 66, no centro da cidade. Nesse momento histórico era notável o crescimento comercial no local, as ruas simples passaram a dar lugar a uma movimentação constante. Dentro desse contexto acontecia o processo de profissionalização na faculdade, as aulas até então eram diurnas (SANTOS, 2011).

O primeiro vestibular, de acordo com Santos (2011), foi inovador, avaliou-se competências, dentre elas principalmente a compreensão, realizada através de prova, avaliação psicológica e entrevistas, a fim de conhecer melhor os candidatos. Houve também nessa época, uma fragmentação do grau acadêmico, criando-se assim duas formações universitárias, licenciatura curta voltada para os professores que iriam atuar apenas no ensino do $1^{\mathrm{O}}$ grau, e a licenciatura plena para aqueles que iriam lecionar no $1^{\mathrm{o}}$ e $2^{\mathrm{o}}$ grau, e que poderiam ser cursadas em um contínuo (FERREIRA, 1982).

O curso de Ciências contava com a participação de vários professores, entres eles professor Carloman Borges e a professora Regina Rosa, nas disciplinas de Matemática. Carloman foi o primeiro doutor em matemática da UEFS. Ferreira (2017) traz que o curso de Ciências tinha apenas três disciplinas de Matemática, sendo as mesmas denominadas de Matemática I, II e III, tendo como docente Carloman Borges, já Prática de Ensino de Matemática I e II eram ministradas pela professora Regina Rosa. A grade do curso de Ciências consistia em:

No currículo do curso Ciências havia 25 disciplinas, distribuídas nos cinco
semestres e nas áreas de Matemática, Química, Física, Biologia e Educação.
Na área de Matemática, constavam as disciplinas Matemática I ( 75 horas),
Matemática II e III (9o horas), Estatística (6o horas) e Desenho geométrico
(45 horas). As disciplinas Prática de Ensino de Matemática I e II eram
ofertadas na forma de estágio supervisionado. (FERREIRA, 2017, p. 43).

Segundo as entrevistas realizadas por Ferreira (2017), em seu levantamento da história da abertura do ensino superior no interior da Bahia, pode-se perceber que os conteúdos trabalhados nas respectivas disciplinas eram equivalentes ao que seria desenvolvido ISSN 2526-2882 
no primeiro e no segundo grau do ensino básico. E o estágio era a prática pedagógica que se tinha na época, acontecendo apenas em uma única disciplina. Os conteúdos específicos da área de matemática, inicialmente, eram:

Matemática I: Revisão dos conceitos fundamentais da aritmética e álgebra (Operações com números inteiros e reais, Progressões, Elementos de Álgebra, Equações de $1^{\mathrm{O}}$ e $2^{\mathrm{O}}$ graus, Sistemas de Equações Lineares, Funções Elementares e seus gráficos).

Matemática II: Revisão dos conceitos fundamentais de Geometria Plana e Espacial, estudo de ângulos, triângulos, quadriláteros, circunferências, círculo, poliedros e principais sólidos geométricos e de suas relações métricas. Matemática III: Introdução ao estudo funções através da revisão de intervalo, produto cartesiano e relação. Estudo de funções: generalidades, gráficos, funções par, impar, crescente, decrescente, composta, inversa, constante, identidade, linear, afim, quadrática, definida por várias sentenças, modular, exponencial, logarítmica e funções circulares, limites (FERREIRA, 2017, p. 45).

No decorrer da investigação pode-se notar nos registros de Ferreira (2017) uma disciplina a mais "Matemática IV" em um quadro comparativo dos semestres, sendo respectivamente no quarto, porém não há descrição dos assuntos abordados na mesma. Além desses conteúdos, as Práticas de Ensino I e II eram destinadas ao estágio supervisionado, dando ênfase aos saberes para ensinar.

A partir de 1974, houve uma mudança na legislação que resultou na extinção das Licenciaturas Matemática, Química, Física e Biologia, que foram completamente substituídas pela licenciatura Plena em Ciências, com habilitação em uma das áreas de conhecimento, para o ensino de $1^{\mathrm{o}}$ e $2^{\mathrm{o}}$ graus. Que foi mais interessante para o governo tanto economicamente, como educacionalmente, sendo uma solução rápida, mesmo sendo alvo de diversas críticas (FERREIRA, 2017).

Com esse panorama histórico visto acima, é possível apontar que a educação superior naquela época foi diferenciada, e que atendeu a curto prazo uma necessidade do estado de ter profissionais aptos para assumir os cargos de professores do ensino básico e da população de obter uma formação superior de fácil acesso, porém não foi a melhor das soluções possíveis, visto que a mesma foi alvo de várias críticas, devido ao baixo custo, em tempo diminuído o que trouxe uma queda na qualidade da formação.

\section{O caderno de Celina Bacellar}

Logo no primeiro acesso ao caderno ele foi digitalizado, com o fim de preservar o material de pesquisa, possibilitando assim estudos futuros sobre o mesmo tema: História da Educação Matemática. Dentro deste tema é importante ressaltar a influência do MMM na formação do professor dessa época, sendo o movimento vigente no ensino da disciplina, que 
incorporou conhecimentos, não vistos antes, como foi descrito por Wielewski (2008), a fim de aproximar a ciência do ensino cotidiano.

O caderno de folhas amareladas, não consta nome de aluno ou professor, também não possui nome da disciplina. De acordo com o ano datado em algumas das folhas 1974, o caderno foi utilizado na FEEFS, no curso de licenciatura curta em Ciências sendo o Carloman Borges o professor da disciplina, conforme mencionou a ex-aluna, Celina Bacellar, em depoimento a Ferreira (2017). O caderno de que se trata o presente estudo é de espiral, possui capa e fundo, feito de material semelhante a papelão.

O mesmo é de matéria única, composto por setenta e uma folhas, sendo destas, duas páginas em branco e uma folha arrancada da qual ficou apenas um pedaço, todas as outras preenchidas por caneta estereográfica azul e lápis, algumas destas páginas ficaram impossibilitadas de serem analisadas, por estarem um tanto apagadas pela ação natural do tempo. Outras estão rasuradas, onde observou-se que por ser feito a caneta, impossibilitado de apagar, a aluna riscava.

Nota-se ao abrir o caderno que o mesmo parece ser uma continuação de um outro caderno que não se teve acesso, pois o mesmo deu início com a demonstração da fórmula da soma e do produto das raízes de uma equação do segundo grau, seguido da continuidade do assunto, como mostra a imagem abaixo.

Figura 1- Soma e Produto das Raízes

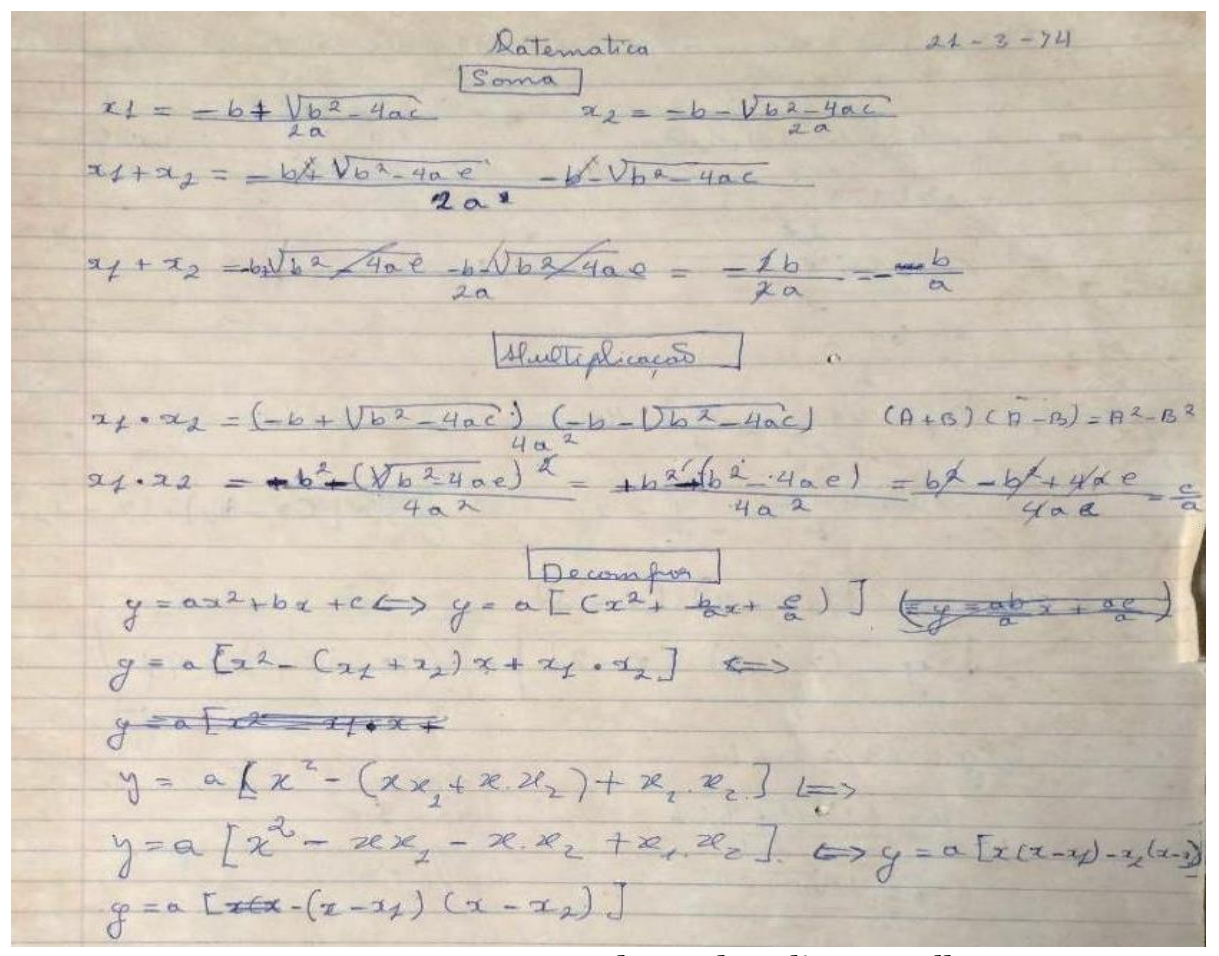

Fonte: Caderno de Celina Bacellar - 1974

O caderno parece ser uma continuação de um outro, pois pode-se notar o registro de duas segundas unidades. Em uma determinada página um tópico com título II unidade, ISSN 2526-2882 
tratando ao longo da mesma do assunto Progressão Geométrica. Em uma outra parte do caderno quando termina Função Exponencial, tem um plano de curso com I, II e III unidade, como pode-se notar nas imagens que se seguem.

\section{Figura 2- Unidade I}

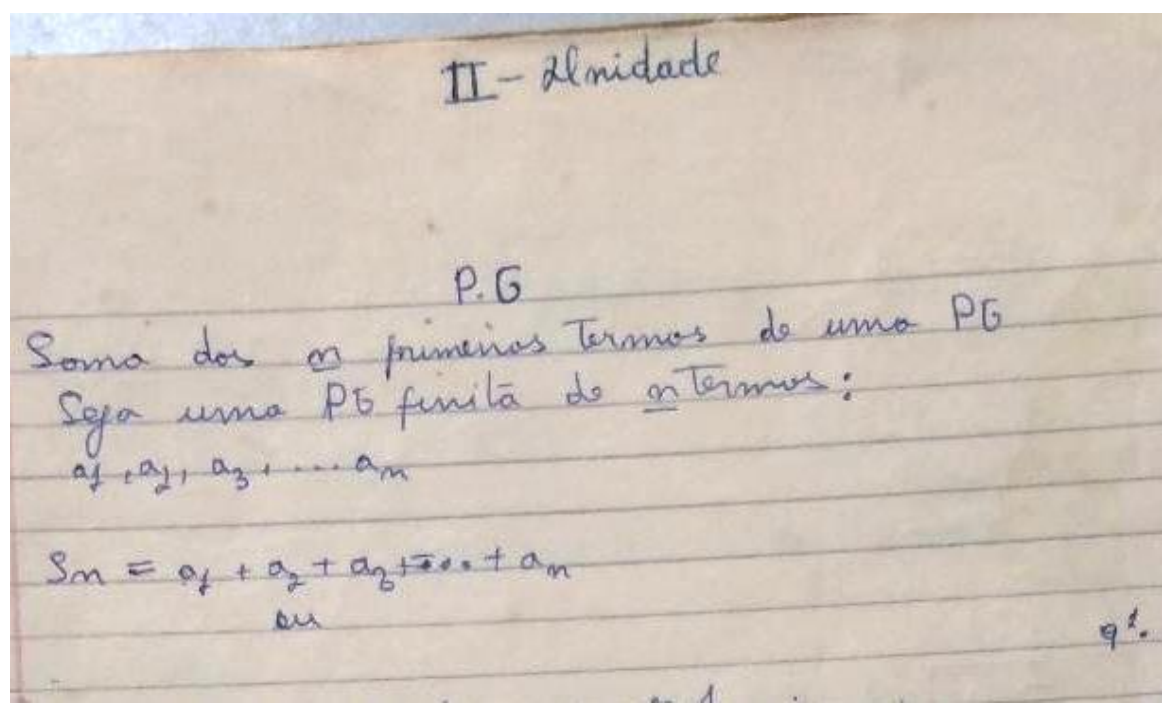

Fonte: Caderno de Celina Bacellar - 1974

Figura 3- Unidade II

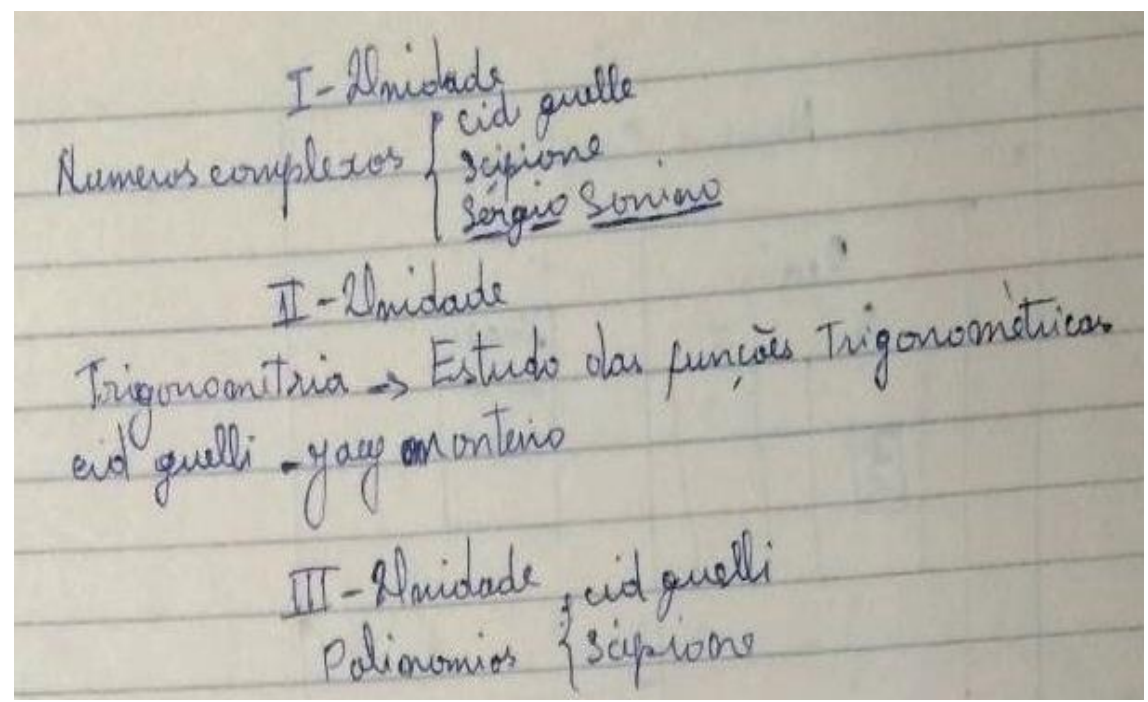

Fonte: Caderno de Celina Bacellar - 1974

Os conteúdos descritos no caderno seguiam esta ordem: Função do Segundo Grau; Progressão Aritmética; Progressão Geométrica; Logaritmo; Equação Exponencial; Números Complexos; Trigonometria; Binômio de Newton; Estatística e Assuntos Pedagógicos. De acordo com o que já foi citado acima, Ferreira (2017) traz os temas que constavam nas disciplinas matemática I, II e III, não sendo identificados todos os que são encontrados no 
caderno, o que pressupõe que o caderno foi utilizado em matemática III e IV, ainda contendo um assunto de matemática I.

O conteúdo de matemática I encontrado no caderno foi Progressões, já de matemática III há Exponencial e Logaritmo, assim fica subentendido que os demais assuntos foram abordados em matemática IV, tal hipótese pode ser verificada por meio da análise dos demais cadernos.

Foi possível perceber que a sequência como foi disposta pelo professor seguia uma ordem diferente do que vemos atualmente, pois primeiro ele aborda Logaritmo para depois introduzir exponencial, já nos dias atuais acontece de forma inversa. O plano de aula é feito pelo docente, da maneira que o preferir, mas não costuma ser realizado nessa ordem nos dias de hoje em função de seguir uma sequência que facilita a assimilação dos conteúdos posteriores.

Nota-se também, que o docente começava um conteúdo, mudava de assuntos em outras aulas e depois voltava para o anterior, como foi o caso de Progressão Aritmética - PA, Progressão Geométrica - PG e Logaritmo, na qual destaco o início de P.A. e após algumas laudas do caderno dá-se início a P.G. e depois em outra página tem uma continuação de P.A., assim como acontece em logaritmo, onde inicia-se o conteúdo, para, e da sequência a soma de P.G. e depois volta para as propriedades de Logaritmo. Em comparação com o que se vê no cotidiano atualmente há uma diferença nos modos de organização dos conteúdos durante as aulas, hoje segue-se finalizando um conteúdo por vez, só passamos para o segundo quando terminamos o primeiro, já na descrição do registro acima percebemos um rodízio de assuntos, o que pode ser fruto do estilo de ensino.

O assunto polinômios não foi identificado como os demais conteúdos, pois estes eram expostos de maneira explicativa, com conceitos e resolução de questões. Apesar do mesmo estar listado na descrição das unidades contidos na imagem 3. O conteúdo de estatística não é apontado como assunto no registro, porém aparece nas últimas folhas do caderno com anotações sobre quartil, percentil e décil. Provável, que o caderno tenha finalizado antes do curso ou período e que possa ter sido substituído, ou que o assunto abordagem tenha sido introdutória para servir como exemplo dentro de um outro conteúdo.

Uma outra observação que pode ser feita está relacionada ao método de ensino utilizado pelo docente da disciplina, que de acordo com o registro se aproxima do que foi definido por Menezes e Santos (2001) como pedagogia tecnicista, na qual os assuntos são passados tecnicamente para os alunos, sendo um mero receptor. A pedagogia tecnicista pode ser percebida, ao longo do caderno, pelos registros no decorrer das aulas, os quais os assuntos eram copiados e exercícios resolvidos, não havendo nenhum indício de um trabalho contextualizado ou envolvendo outros instrumentos além do quadro e o caderno. Porém, como 
foi descrito acima por Luz e Rios (2017) sobre o meio de acesso a uma realidade que já foi vivenciada, não se pode confirmar que Carloman Borges era adepto desse método, aqui está sendo presumido através da análise dos registros.

\section{Progressões: uma abordagem}

Após o término de uma questão cujo assunto era inequação do segundo grau, dá-se início ao conteúdo de progressões, o professor Carloman começou com Progressão Aritmética (P.A.) introduzindo a seguinte sequência: 2, 4, 6, 8, 10, 12. Nota-se aqui que o professor não definiu, nem conceituou o que seria uma sequência, partindo dos saberes a ensinar (conteúdo matemático), como citado por Valente (2017). No entanto, o mesmo utilizou do seu conhecimento dos saberes para ensinar, momento em que opta por essa metodologia, pressupondo que os alunos teriam um melhor entendimento do conteúdo.

Nos livros observados Matemática Na Escola Renomada de Di Pierro Netto e Goes ${ }^{124}$ (1973) e Matemática Curso Moderno de Monteiro ${ }^{125}$, Duarte ${ }^{126}$ (1972) os autores partem da premissa explicativa, dizendo o que é uma sequência, trazendo definições e exemplificações. A partir da sequência dada pelo professor regente, o mesmo define Progressão Aritmética, conforme registro escrito "Uma progressão aritmética (P.A.) é uma sequência (finita ou infinita)" e traz a dedução via indução matemática da fórmula geral, onde:

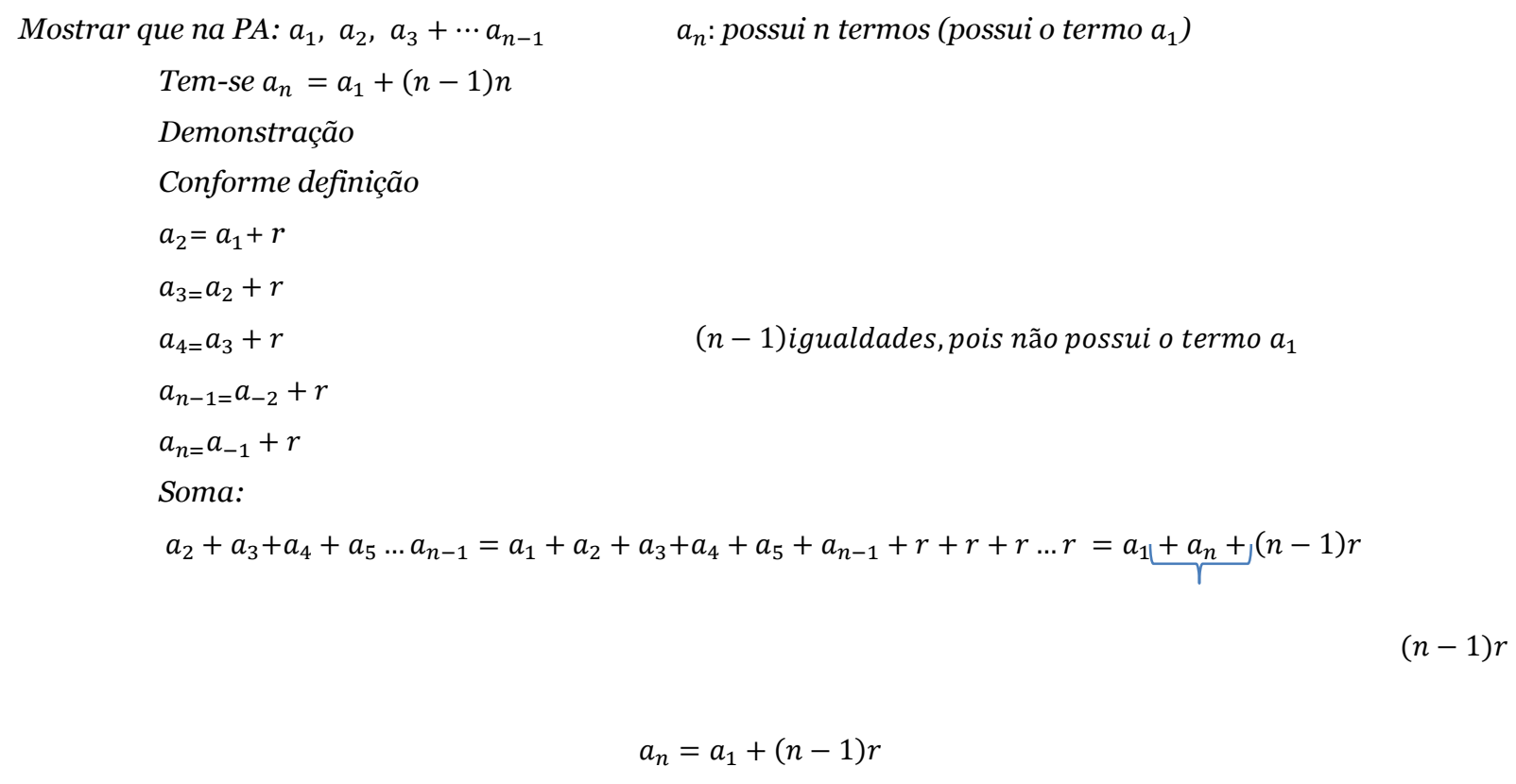

\footnotetext{
${ }^{124}$ Célia Contin Góes, também foi professora do Colégio de Aplicação da USP, tendo publicado com Di Pierro Netto os três volumes da Coleção Matemática na Escola Renovada

125 Jacy Monteiro (1921-1975) foi professor de matemática e cursou ciências matemáticas na Faculdade de Filosofia, Ciências e Letras da Universidade de São Paulo
} 


\section{Fonte: Caderno de Celina Bacellar - 1974}

Seguido de exercícios para aplicações das fórmulas que foram dadas (figura 4), podemos observar nesses registos traços da pedagogia tecnicista pela forma como era abordado o assunto, primeiro exposição de conteúdos e logo em seguida questões, tornando o aluno um mero expectador do conhecimento, não havendo sinais de uma estimulação para uma investigação na matemática (MENEZEZ; SANTOS, 2001).

Figura 4 - Exercícios de P.A.

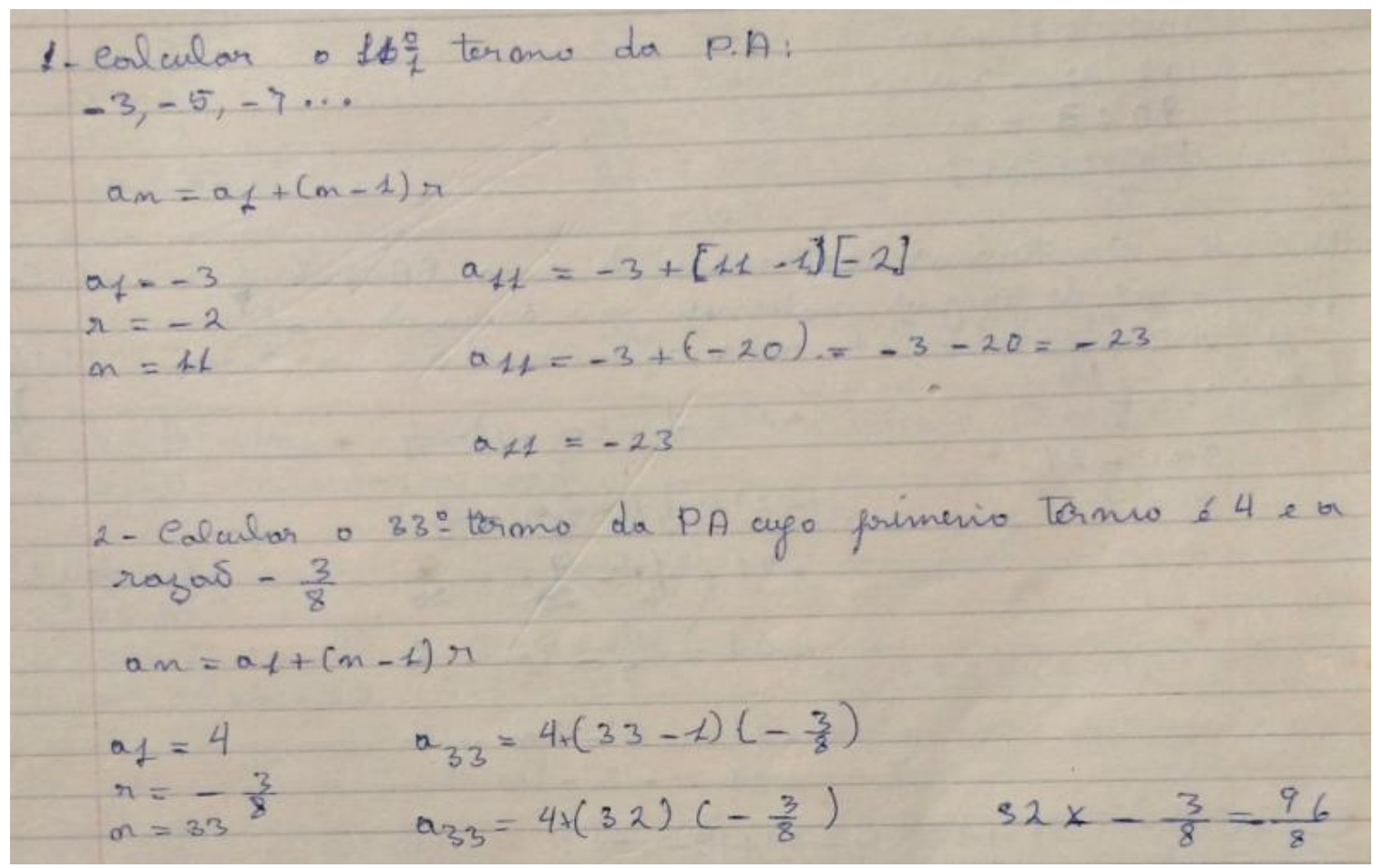

Fonte: Caderno de Celina Bacellar - 1974

Scipione (1992) denomina progressões aritméticas e progressões geométricas de sequências aritméticas e geométricas respectivamente. A autor relata que a definição dessas sequências foi feita através da lei de recorrência, onde para calcular (um termo qualquer) é necessário calcular todos os termos anteriores. Mesmo após essa explicação, o autor demonstra por indução, sendo este o mesmo método utilizado por Carloman. Já Jacy Monteiro (1973) introduz sequências utilizando conjuntos numéricos, assim como em progressões. Ao término de P.A. o Carloman segue o mesmo padrão explicativo para ensinar Progressões Geométricas (P.G.), como podemos ver na imagem abaixo.

O conteúdo de P.G

Figura 5- Conteúdo de P.G. 


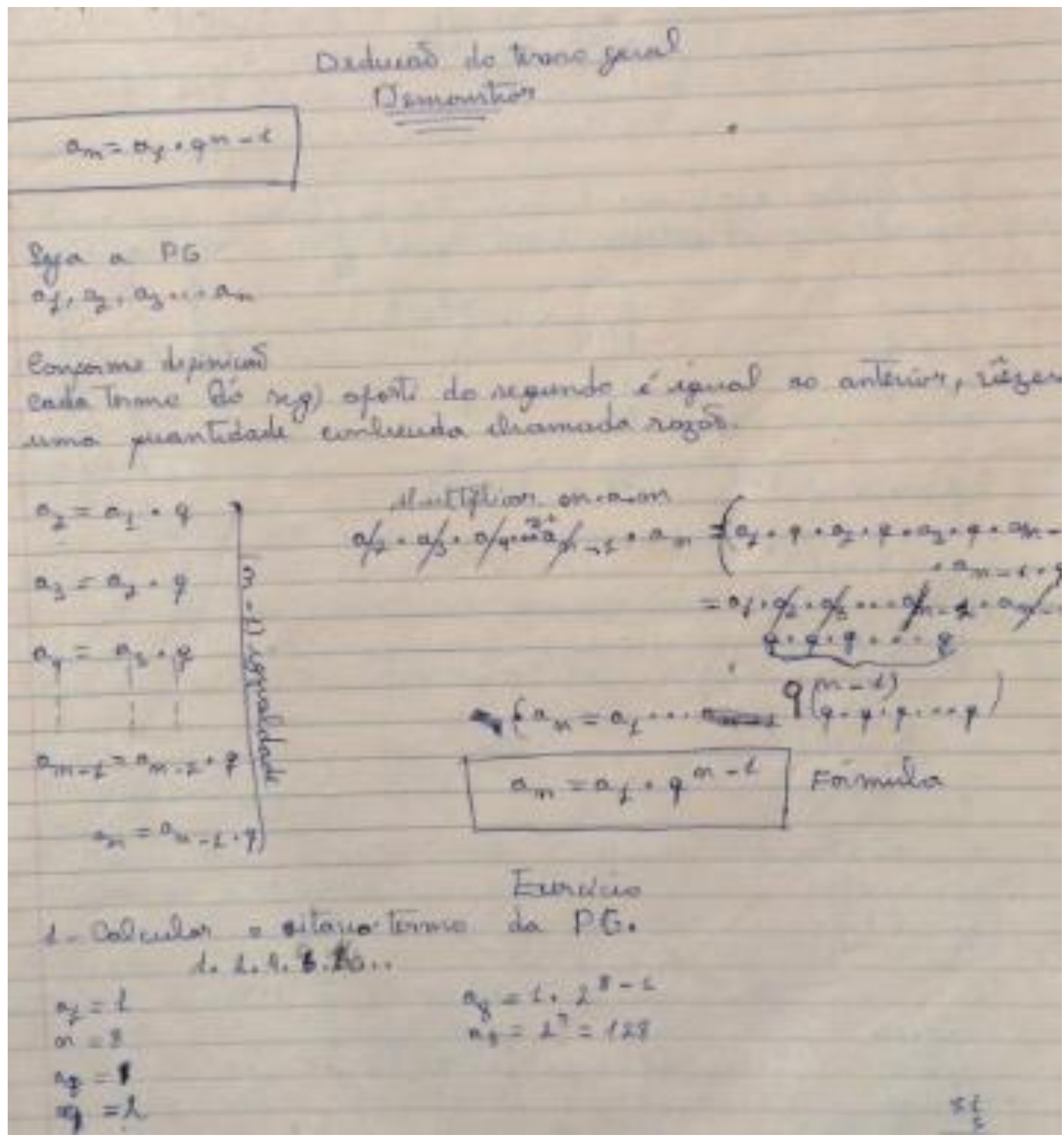

Fonte: Caderno de Celina Bacellar - 1974

A análise de progressões através do caderno demonstra que o professor regente utilizava uma prática pedagógica paralela a dos demais autores citados, trazendo definição, termo geral, propriedades e soma de progressões, diferenciando-se como já supracitado o conteúdo de sequência e de alguns subtópicos. No entanto não quer dizer que o professor não trouxe os demais assuntos para a sala de aula, como por exemplo, o professor não colocou uma explicação sobre interpolação e termos equidistantes de P.A. e P.G., mas trouxe nos exercícios, assim como os demais, como mostra o quadro abaixo: 
Quadro 1 - Comparação entre livros e o caderno

\begin{tabular}{|c|c|c|c|}
\hline Conteúdos & Matemática na Escola & Matemática Curso Moderno & Caderno de Celina \\
\hline Sequências & $\begin{array}{l}\text { - Definição. } \\
\text { - Notação. } \\
\text { - Determinação. } \\
\text { - Crescimento. } \\
\text { - Representação gráfica. } \\
\text { - Convergência. }\end{array}$ & $\begin{array}{l}\text { - Exemplos preliminares } \\
\text { - Definição } \\
\text { - Sequência crescente e } \\
\text { decrescente }\end{array}$ & \\
\hline $\begin{array}{l}\text { Progressões } \\
\text { Aritméticas }\end{array}$ & $\begin{array}{l}\text { - Definição. } \\
\text { - Termo geral. } \\
\text { - Classificação. } \\
\text { - Gráfico. } \\
\text { - Propriedades. } \\
\text { - Soma dos n primeiros } \\
\text { termos. } \\
\text { Exercícios. }\end{array}$ & $\begin{array}{l}\text { - Definição. } \\
\text { - Cálculo do n-ésimo termo } \\
\text { de uma P.A. } \\
\text { - Interpolação aritmética. } \\
\text { - Termos equidistantes dos } \\
\text { extremos. } \\
\text { - Soma dos n primeiros } \\
\text { termos. }\end{array}$ & $\begin{array}{l}\text { - Problemas. } \\
\text { - Dedução do termo } \\
\text { geral da P.A. } \\
\text { - Propriedades da P.A. } \\
\text { - Soma n-ésima dos } \\
\text { termos de uma P.A. } \\
\text { - Exercícios. }\end{array}$ \\
\hline $\begin{array}{l}\text { Progressões } \\
\text { Geométricas }\end{array}$ & $\begin{array}{l}\text { - Definição. } \\
\text { - Termo geral. } \\
\text { - Classificação. } \\
\text { - Propriedades. } \\
\text { - Soma dos n primeiros } \\
\text { termos. } \\
\text { - limite da soma dos termos. } \\
\text { - Produto dos n primeiros } \\
\text { termos } \\
\text { - Exercícios. }\end{array}$ & $\begin{array}{l}\text { - Definição. } \\
\text { - Cálculo do n-ésimo termo } \\
\text { de uma P.G. } \\
\text { - Interpolação geométrica. } \\
\text { - Termos equidistantes dos } \\
\text { extremos. } \\
\text { - Soma dos n primeiros } \\
\text { termos. }\end{array}$ & $\begin{array}{l}\text { - Dedução do termo } \\
\text { geral da P.G. } \\
\text { - Exercícios. } \\
\text { - Soma de P.G. finita }\end{array}$ \\
\hline
\end{tabular}

Fonte: Elaborado pelos autores.

Nota-se no decorrer das datas no caderno que o professor regente segue um estilo específico e marcadamente teorizado pelos estudiosos da época em meados de 1970 (MENEZEZ; SANTOS, 2001). Um fato que não se pode deixar passar, é que, neste conteúdo, não se observou traços do MMM nos registros de Celina. Não houve uma incorporação de novos assuntos, nem uma relação mais profunda dos conteúdos que aparecem no objeto de análise (WIELEWSKI, 2008).

O caderno de Celina se mostra como importante objeto de estudo para compreender a História da Educação Matemática e da formação de professores, o presente trabalho se propôs a analisar historicamente o conteúdo progressões aritmética e geométrica presentes no caderno da disciplina Matemática do Curso de Ciências da Faculdade Estadual de Educação de Feira de Santana (FEEFS). Desse modo, demonstrou importância e trouxe conteúdos relevantes que podem vir a contribuir para o estudo historiográfico da Educação Matemática, em relação aos conteúdos de progressões, porém vale ressaltar a complexidade deste instrumento e a necessidade de dar continuidade em demais pesquisas.

\section{Algumas considerações...}

O caderno de Celina Bacelar, aqui analisado, foi utilizado no ano de 1974, na Faculdade Estadual de Feira de Santana uma das instituições de ensino pioneiras na cidade. O curso em que fazia parte, tinha como objetivo formar um professor de ciências com atuação na 
área de matemática. Naquele momento histórico a demanda por professores de ensino básico no mercado de trabalho era alarmante, o que culminou na criação de faculdades com cursos de licenciatura curta, representando uma solução emergencial.

Pode-se notar no conteúdo registrado no caderno muitos aspectos importantes do cotidiano do processo profissionalizante de professores, como por exemplo; atividades, práticas pedagógicas e metodologias de ensino, as escrituras feita pela aluna traz suas marcas pessoais nas anotações do conteúdo exposto e detalhamento das atividades feitas pela mesma.

Sobre os conteúdos abordados no caderno, trata-se de assuntos que iriam ser ministrados no ensino médio. Ainda vemos nos dias atuais traços da metodologia adotada pelo professor, que se assemelha muito com o que era teorizado pela pedagogia tecnicista, não se pode afirmar que o método foi o melhor ou que teve maior êxito na vida do estudante, pois cada indivíduo interpreta de maneira particular o seu aprendizado.

Quanto ao objetivo proposto, há diferenças no modo de ensinar matemática daquela época para os dias atuais, embora as pequenas alterações tenham facilitado o entendimento e a interpelação entre conteúdo, o que impacta diretamente na formação dos professores, visto que estes são saberes que constroem a prática profissional futura. Nesse panorama, percebese como o momento histórico e econômico dá época influencia diretamente na política educacional, tanto no ensino superior como na solução oferecida ao ensino básico. O modelo de licenciatura curta, foi muito criticado em função do tempo limitado de estudo, e pela formação generalista, o que trouxe como consequência um menor aprofundamento teórico. Dessa forma, esse foi um marco pra a interiorização do ensino superior, permitindo o acesso desta população à educação especializada e às melhores condições de trabalho, dado a realidade dá época.

A análise do caderno trouxe algumas limitações, entre elas o acesso restrito apenas do que foi escrito por uma aluna, ficando assim a serviço de estudos futuros um maior aprofundamento com entrevista, entre outros modos de investigação a fim de conhecer mais a realidade que foi vivenciada. Esse estudo apresenta relevância para uma historiografia da matemática, em particular, da educação matemática, no âmbito da profissionalização do professor de matemática ao trazer mais elementos para uma constituição desse processo, em especial, na Bahia.

\section{Referências}

BOAVENTURA, E. M. A construção da universidade Baiana: origens, missões e afrodescendência. Salvador: EDUFBA, 2009. 
CHAPANI, D. T. A formação de professores na gênese do sistema estadual de ensino superior da Bahia. Revista Brasileira de História da Educação, CampinasSP, v. 12, n. 1 (28), p. 145-166, jan./abr. 2012.

COSTA, R. R; AMARAL, W. A. Os cadernos de normalista no estado do Paraná na década de 1970: sinais e vestígios de como ensinar a matemática. HISTEMAT - ANO 3, n. 1, 2017.

DI PIERRO NETTO, S.; GOES, C. C. Matemática na escola renovada: $2^{\mathrm{a}}$. Série do $2^{\circ}$. grau. São Paulo, SP: Saraiva, 1973. 3v

DUARTE, A. R. S. Luiz Henrique Jacy Monteiro e o ensino secundário de matemática. Revista Brasileira de História da Matemática, São Paulo, v.12, n.24, p. 55-70, abr./ago. 2012.

FERREIRA, E. F. Licenciatura de curta duração: Solução Emergencial ou definitiva? Sitientibus, Feira de Santana, 2(3): 155-163, jul/dez, 1983.

FERREIRA, J. L. Fios, retalhos e pontos: tecituras sobre a profissionalização docente em matemática em Feira de Santana (1970-1991). Salvador, 2017. 172f. Tese (Doutorado em Ensino, Filosofia e História das Ciências) - Programa de Pós-Graduação em Ensino, Filosofia e História das Ciências, Universidade Federal da Bahia e Universidade Estadual de Feira de Santana. Salvador, 2017.

FRANCISCO, P. R.; NACARATO, A. M. A (Des)Profissionalização do Professor de Matemática: análise de quatro casos. In: ENCONTRO BRASILEIRO DE ESTUDANTES DE PÓSGRADUAÇÃO EM EDUCAÇÃO MATEMÁTICA (EBRAPEM), 12, Rio Claro. Anais... Rio Claro, SP: UNESP, 2008.

LUZ, L. B.; RIOS, D. F. Investigando cadernos escolares: os problemas aritméticos presentes em um caderno gaúcho de segundo ano primário (1959). In: SEMINÁRIO TEMÁTICO CADERNOS ESCOLARES DE ALUNOS E PROFESSORES E A HISTÓRIA DA EDUCAÇÃO MATEMÁTICA, 1890-1990, 15, Pelotas. Anais... Pelotas, RS: UFPel, 2017.

MENEZES, E. T.; SANTOS, T. H. Verbete pedagogia tecnicista. Dicionário Interativo da Educação Brasileira - Educabrasil. São Paulo: Midiamix, 2001. Disponível em: <http://www.educabrasil.com.br/pedagogia-tecnicista/>. Acesso em: 01 de mai. 2018.

MONTEIRO, L. H. Jacy. Matemática curso moderno: segundo grau. [São Paulo]: Nacional, 1972. $2 \mathrm{v}$

NÓVOA, A. Profissão professor. Porto: Porto Editora, 1992.

RHEINHEIMER, J. M.; DALCIN, A. Análise de um caderno de matemática de 1917 do curso médio da escola complementar de porto alegre. XV Seminário ISSN 2526-2882 
Temático Cadernos escolares de alunos e professores e a história da educação matemática, 1890-1990. Pelotas - Rio Grande do Sul, 2017, UFP.

QUEIROZ, R. T. U.; ZUIN, E. S. L. Equação/função exponencial em dois livros didáticos antes e durante o movimento da matemática moderna. In: $15^{\circ}$ Seminário Nacionnal de História da Ciência e da tecnologia, 2016, Santa Catarina. Anais... Santa Catarina: PUC, 2016, p. 1-17

RIOS, D. F.; FISCHER, M. C. B. CADERNOS DE BEATRIZ: discussões teóricas para uma aproximação com a matemática nos registros de estágio da normalista gaúcha (1967). HISTEMAT - ANO 3, N. 1, 2017.

SANTOS, A. M. F. Uma Aventura Universitária no Sertão Baiano: da Faculdade de Educação à Universidade de Feira de Santana. Salvador, 2011. 324f. Tese (Doutorado em Educação) - Programa de Pós-Graduação em Educação, Universidade Federal da Bahia. Salvador, 2011.

VALENTE, W. R. Dos livros didáticos para os cadernos de matemática: a emergência dos saberes profissionais. Zetetiké, Campinas, SP, v.25, n.2, maio/ago.2017, p.254-264.

VALENTE, W. R. Os saberes para ensinar matemática e a profissionalização do educador matemático. Revista Diálogo Educacional, Curitiba, PR, v. 17, n. 51, p. 207-222, jul. 2017.

VALENTE, W. R. (Orgs.). A Matemática Moderna nas escolas do Brasil e de Portugal: primeiros estudos. São Paulo: Editora Da Vinci, 2007.

WIELEWSKI, Gladys Denise. O movimento da matemática moderna e a formação de grupos de professores de matemática no Brasil. In: ProfMat2008 Actas. Lisboa, Portugal: Associação de Professores de Matemática, 2008. p.1-10.

\section{Biografia Resumida}

Ikaro de Oliveira Trabuco: Licenciado em Matemática pela Universidade Estadual de Feira de Santana (UEFS).

Link Lattes: http://Link Lattes.cnpq.br/1148595693068209

e-mail: ikarotrabuco@hotmail.com

Joubert Lima Ferreira: Licenciado em Matemática pela Universidade Estadual de Feira de Santana (UEFS). Mestre e Doutor em Ensino, Filosofia e História das Ciências pela Universidade Federal da Bahia/UEFS. Atualmente é professor da área de Educação Matemática no Centro das Ciências Exatas e ISSN 2526-2882 
das Tecnologias (CCET) da Universidade Federal do Oeste da Bahia (UFOB). Coordenador do Laboratório de Inovação e Pesquisa em Educação Matemática (LIPEM) da UFOB, certificado junto ao CNPq.

Link Lattes: http://Link Lattes.cnpq.br/8482327357397338 e-mail: joubert.ferreira@ufob.edu.br 